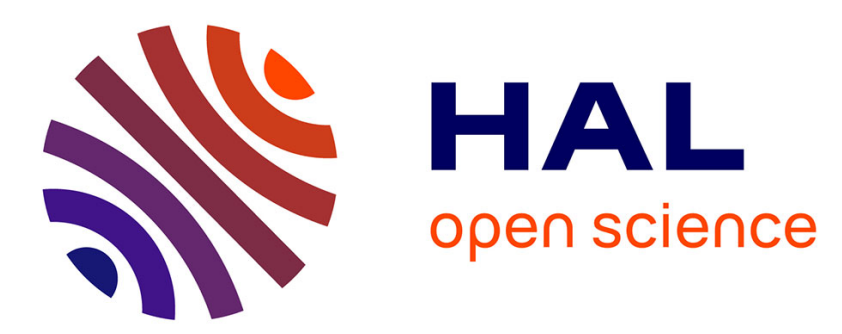

\title{
A growth and yield model for even-aged Pinus brutia Ten. stands in Syria
}

Shater, De-Miguel, Kraid, Pukkala, Palahí

\section{To cite this version:}

Shater, De-Miguel, Kraid, Pukkala, Palahí. A growth and yield model for even-aged Pinus brutia Ten. stands in Syria. Annals of Forest Science, 2011, 68 (1), pp.149-157. 10.1007/s13595-011-0016-z . hal-00930731

\section{HAL Id: hal-00930731 \\ https://hal.science/hal-00930731}

Submitted on 1 Jan 2011

HAL is a multi-disciplinary open access archive for the deposit and dissemination of scientific research documents, whether they are published or not. The documents may come from teaching and research institutions in France or abroad, or from public or private research centers.
L'archive ouverte pluridisciplinaire HAL, est destinée au dépôt et à la diffusion de documents scientifiques de niveau recherche, publiés ou non, émanant des établissements d'enseignement et de recherche français ou étrangers, des laboratoires publics ou privés. 


\title{
A growth and yield model for even-aged Pinus brutia Ten. stands in Syria
}

\author{
Zuheir Shater • Sergio de-Miguel • Bassel Kraid • \\ Timo Pukkala • Marc Palahí
}

Received: 5 January 2010 /Accepted: 10 June 2010 / Published online: 15 February 2011

(C) INRA and Springer Science+Business Media B.V. 2011

\begin{abstract}
Pinus brutia Ten. subspecies brutia, which occurs in the Eastern Mediterranean region, is the main forest species in Syria and important for multi-purpose forestry. In this study, 6,631 10-year past growth diameter increment measurements were taken in 83 temporary sample plots. The current breast height diameter of all trees was measured and a sample of trees was measured for height and age. The plots were placed so as to capture the whole range of variation in site quality, stand age and stand density. The data were used to develop the following models:

- Dominant height model: the guide curve method was used to fit an anamorphic site index model between stand age and dominant height.

- Individual-tree diameter increment model: future 10year diameter increment was modelled as a function of
\end{abstract}

Associate Editor: Matthias Dobbertin

\section{Z. Shater}

Department of Forestry and Ecology, Faculty of Agriculture, University of Tishreen,

Latakia, Syria

S. de-Miguel $\cdot$ T. Pukkala

Faculty of Science and Forestry, University of Eastern Finland,

P.O. Box 111, 80101 Joensuu, Finland

\section{S. de-Miguel $(\square)$}

Centre Tecnològic Forestal de Catalunya,

Ctra. Sant Llorenç de Morunys, km. 2,

25280 Solsona, Spain

e-mail: sergio.demiguel@ctfc.es

B. Kraid

Department of Forestry and Ecology, Faculty of Agriculture, University of Aleppo,

Aleppo, Syria

\section{Palahí}

European Forest Institute, Mediterranean Regional Office,

C/ Castella, 33, esc. B, $3^{\circ}-2$,

08018 Barcelona, Spain site index, stand basal area, basal area of trees larger than the subject tree, slope, aspect and diameter at breast height (dbh).

- Tree height model: tree height was modelled as a function of dbh, dominant height and dominant diameter.

- Self-thinning: the plots which have reached the selfthinning limit were selected and the (maximum) number of trees per hectare was modelled as a function of mean diameter and site index.

The set of models enables the simulation of forest stand dynamics on an individual-tree basis.

Keywords Calabrian pine $\cdot$ Individual-tree model .

Mediterranean forestry $\cdot$ Stand dynamics $\cdot$ Turkish red pine

\section{Introduction}

Pinus brutia forests are important for multi-purpose forestry and have a high ecological value (Panetsos 1985). They are of high economic importance and represent the only or the main source of wood and forest cover in some Mediterranean countries (Gezer 1985; Fischer et al. 2008). In Turkey and other East-Mediterranean countries, it is the most important conifer species from the economic point of view; its wood is used for many purposes: construction, industry, carpentry, firewood and pulp (Fady et al. 2003; Petrakis et al. 2007; Tolunay et al. 2008). In Syria, where the use of forests has traditionally been multi-objective, $P$. brutia has additional economic importance due to the oleoresins that can be extracted and used in soap, polish and pharmaceutical industry (Madi 1999). Furthermore, brutia pine forests have a key role in providing important indirect benefits and environmental services such as protection of soil and water resources, conservation of biological diversity, support to agricultural productivity, carbon sequestration, climate change 
mitigation and adaptation, and combating desertification. The capability of $P$. brutia to grow on a wide range of soils and elevations, as well as its growth potential, make it one of the most promising pine species not only in Syria, but also in other regions within the Mediterranean Basin. Furthermore, its ability of withstanding aridity and continentality and of regenerating after wild fires makes it an irreplaceable forest species within the fragile Mediterranean ecosystems (Fischer et al. 2008).

Despite the relevant functions of Syrian forests, they seldom have a management plan. Only in the most recent decades, management plans have been prepared and conservation measures undertaken to promote sustainable use of $P$. brutia forests (Fischer et al. 2008). Current forest planning in Syria deals only with timber production and uses computationally simple methods. No computational methods exist that would allow the foresters to compare different management options. Alternative silvicultural systems, such as evenaged forestry with clear-felling and selection cuttings, are used depending on the species and management objectives. In fact, the Syrian forest policy during the last few decades has mainly focused on preserving the existing natural forests and establishing new plantations, and has possibly led to a current sub-exploitation of $P$. brutia forest resources.

In view of the importance of $P$. brutia in Syria, there is a need for a reliable system of growth and yield predictions that, with appropriate economic parameters and ecological models, will support multifunctional forest management and planning. Traditionally, the prediction of forest growth and yield in Syria has been based on experience, historical records and extrapolation of yield tables. However, these approaches may not be sufficient when developing sound management plans for complex forest systems. Of the modelling approaches, individual-tree growth modelling enables the most flexible and detailed simulation of the complex structures of Mediterranean forests and their dynamics.

The aim of this study is to develop a system of models that allow managers to simulate the dynamics of $P$. brutia stands in Syria. The model set includes a site index model, individualtree diameter increment and height models, and a self-thinning model. The model set will allow managers to predict the harvests and future stand development in alternative treatment schedules providing valuable support for silvicultural decision-making.

\section{Materials and methods}

\subsection{Sample plots}

Sixty-four temporary plots were measured in the coastal mountains of Syria, where most P. brutia forests of the country can be found. Another 19 plots were measured for stand age and dominant height to complement the data that were used to model the relationship between stand age and dominant height (Table 1). However, three observations representing very poor sites and old stands were removed from the data, since their inclusion had removed the balance between good and poor sites in old age classes.

The sample plots were selected so as to capture the whole range of variation in site, stand age and stand density. Correlation between stand age and site quality was avoided (for instance, measuring young stands mainly on good sites and old stands mainly on poor sites would cause bias in modelling).

The sample plots were circular. The plot radius was varied depending on the stand density so that $50-75$ trees were measured in most plots. The following variables were recorded for each tree: tree species; diameter at breast height (dbh); radial growth of one or two past 10-year periods; tree height of 10-11 sample trees; age of five dominant trees; and bark thickness of 10-11 sample trees. The following additional variables were recorded in each plot: altitude, slope and aspect; parent rock type; soil depth (five measurements in different parts of the plot, one in the plot centre and four around it); and UTM coordinates of the plot centre.

The first step of analysing the data was to fit a plot-wise model for tree height. The model was as follows:

$h=1.3+d^{2} /(a+b \times d)^{2}$

where $h$ is tree height (metres) and $d$ is diameter at breast height (centimetres). These models were used to calculate the height of trees for which height was not measured. Another model was fitted between single bark thickness and diameter. This model was used to calculate the bark thickness of all trees. Bark thickness was required to convert the measured under-bark radial growths into estimates of over-bark diameter growth. The bark model was common for all plots. The model was as follows:

bark $=0.102+0.769 \times d$

where bark is bark thickness (millimetres) and $d$ is dbh (centimetres).

\subsection{Site index modelling}

The ages and dominant heights calculated for the plots were used to fit a model for dominant height development on average site. Dominant height was defined as the mean height of 100 thickest trees per hectare.

Methods for quantifying site quality can be classified into (1) direct methods and (2) indirect methods. Direct methods require the existence of the species of interest at 


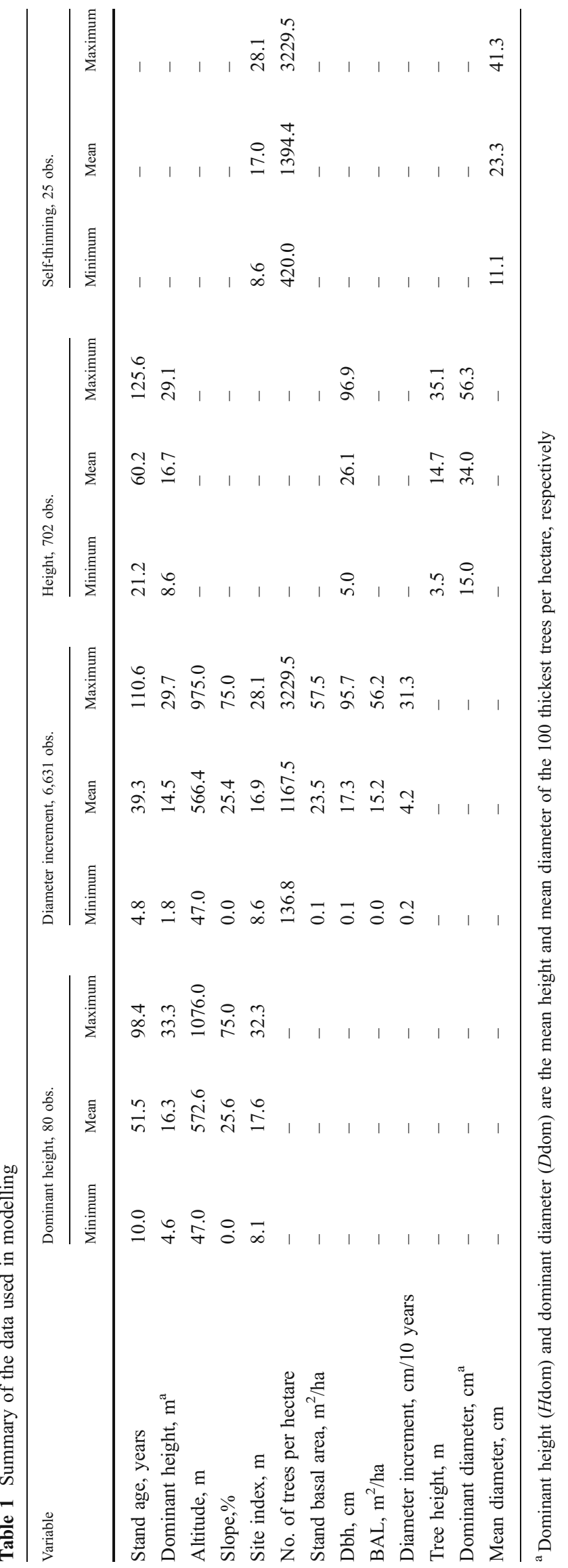

the particular location where site quality is to be evaluated (Clutter et al. 1983). The most commonly used direct method for estimating site quality relies on site index equations. Since only one dominant height measurement was available in Syria, the site quality was assessed by using the guide curve method in order to generate anamorphic site index curves (Clutter et al. 1983). Several functions such as Hossfeld I, modified Hossfeld I and Smalian (cited by Peschel 1938), Strand (Strand 1964) and Chapman-Richards (Pienaar and Turnbull 1973) were tested. The selection among the candidate equations was based on fitting statistics and biological considerations such as the value of the asymptote, and the growth pattern at young ages when compared to the modelling data. Assuming an anamorphic relationship between dominant heights of different sites, a site index was calculated for every plot using 50 years as the index age.

\subsection{Diameter increment modelling}

The data set used for diameter increment modelling (Table 1) included 6,631 observations. The number of trees measured for past growth was slightly more than $50 \%$ of this number, since only one 10 -year growth was measured in some plots. The purpose was to develop the following type of model for the future 10-year diameter increment:

$i_{\mathrm{d}}=f($ tree size, site quality, competition $)$

where $i_{\mathrm{d}}$ is future 10 -year diameter increment (centimetres). Each type of predictors (tree size, site, competition) was described with several variables.

When preparing data for diameter increment modelling, the steps of processing individual-tree data were as follows: (1) The doubled bark thickness (calculated with the bark model) was subtracted from the measured diameter to obtain under-bark diameter; (2) the doubled measured radial growth was subtracted from under-bark diameter to obtain underbark diameter 10 years ago; (3) the under-bark diameter was converted into over-bark diameter by assuming that the ratio between over- and under-bark diameters was 10 years ago the same as now; (4) 10-year diameter increment (over-bark) was obtained as a difference of two over-bark diameters (the present dbh minus the dbh 10 years ago).

Ten years were subtracted from the current stand age to get stand age 10 years ago. The stand characteristics (basal area, mean diameter, etc.) were calculated from tree dimensions 10 years ago. If two 10 -year past growths were measured, the same calculation process was repeated to get tree and stand status 20 years ago, and future 10-year overbark diameter increment 20 years ago.

Tree growth dynamics are inherently nonlinear. However, linear regression is a suitable tool for modelling growth curves 
if a linear relationship is found among the key variables and biologically reasonable shapes are determined (Trasobares et al. 2004). Variables describing tree size, competition and site quality were used to explain diameter growth. The predictors represented the tree level (diameter at breast height, basal area of trees larger than the subject tree, etc.) and the stand level (basal area, number of trees per hectare, and site characteristics).

Due to the hierarchical structure of the data (trees of the same plot were correlated observations) a mixed model of the following type was fitted to the data:

$i_{d, i j}=f\left(\mathbf{x}_{i j}\right)+u_{j}+e_{i j}$

where $i_{\mathrm{d}, i j}$ is the growth of tree $i$ of plot $j, \mathrm{f}\left(x_{i j}\right)$ is the fixed model, $\mathbf{x}_{i j}$ a vector of predictors calculated for tree $i$ of plot $j, u_{j}$ is a random plot factor (describing the deviation of plot $j$ from the overall growth level) and $e_{i j}$ is residual (that part of the growth of tree $i$ of plot $j$, which cannot be explained by the model). Then, another model was fitted to predict the plot factor $\left(u_{j}\right)$ from site characteristics such as site index, soil depth, parent rock type and slope. As an alternative, an ordinary least squares (OLS) model was fitted to the same data.

\subsection{Height modelling}

All height measurements of the plots (702 observations) were used to model tree height as a function of diameter at breast height, dominant height and dominant diameter (Table 1). The model was static and was fitted by using nonlinear regression analysis.

\subsection{Self-thinning modelling}

According to Reineke's expression (Reineke 1933) and the $-3 / 2$ power rule of self-thinning (Yoda et al. 1963), a $\log -\log$ plot of the average tree size and stem density will follow a straight self-thinning line of a constant slope. According to Hynynen (1993), the slope of the line varies for different tree species, while the intercept of the selfthinning line varies within tree species according to site index. In this study, the self-thinning model was developed by selecting the plots which were assumed to be on the self-thinning limit. In order to do so, the plots with highest stand density were chosen, and field observations were used to confirm that self-thinning had begun in those plots. The plots were first divided into three site quality classes according to site index: good (site index (SI) $>20 \mathrm{~m}$ ); medium (SI 15-20 m); and poor $(\mathrm{SI}<15 \mathrm{~m})$. The plots that were assumed to be on the self-thinning limit were selected separately in each SI category. This resulted in 25 plots for modelling the self- thinning limit (Table 1). A model between the number of trees and the mean diameter was fitted by using the OLS method. The influence of site quality on the intercept of the self-thinning line was examined by adding the site index to the model as an independent variable.

\subsection{Model evaluation}

The following criteria were considered in model evaluation: (a) biological soundness, i.e. agreement with current biological knowledge; (b) logical behaviour of the model set in extrapolations and long-term simulations; (c) simplicity and robustness and (d) statistical significance and precision and non-biasness. This last criterion took into account $(1)$ high significance of all predictors $(p<0.05)$ and high $F$ value of the model and (2) logical signs of regression coefficients. It was also required that site, tree size and competition were included in the diameter increment model (at least one predictor in each group).

\section{Results}

\subsection{Model for dominant height}

The developed dominant height model shows the average dominant height development on all plots (guide curve). Dominant height developments of other sites can be obtained by multiplying the guide curve by a factor lower (poor sites) or higher (good sites) than one. The fitted Strand, modified Hossfeld I and Smalian models were not s-shaped and caused an overestimation of the height growth in young stands. Hossfeld I was initially s-shaped predicted decreasing dominant heights in very old stands, which is not logical from the biological point of view. Finally, a model for the average dominant height development was fitted following the Chapman-Richards equation (Pienaar and Turnbull 1973) which was the most consistent statistically and biologically (Fig. 1):

$H$ dom $=18.299\left(1-\mathrm{e}^{-0.080 T}\right)^{1.976}$

where $H$ dom is the guide curve value of dominant height (metres) and $T$ is the stand age (years). Site index is the dominant height of the stand at an index age. The index age was taken as 50 years. Therefore, the site index of a stand can be calculated as follows:

$$
\begin{aligned}
\mathrm{SI} & =\frac{H \operatorname{dom}}{H \operatorname{dom}(T)} H \operatorname{dom}(50) \\
& =H \operatorname{dom} \frac{(1-\exp (-0.080 \times 50))^{1.976}}{(1-\exp (-0.080 \times T))^{1.976}}
\end{aligned}
$$




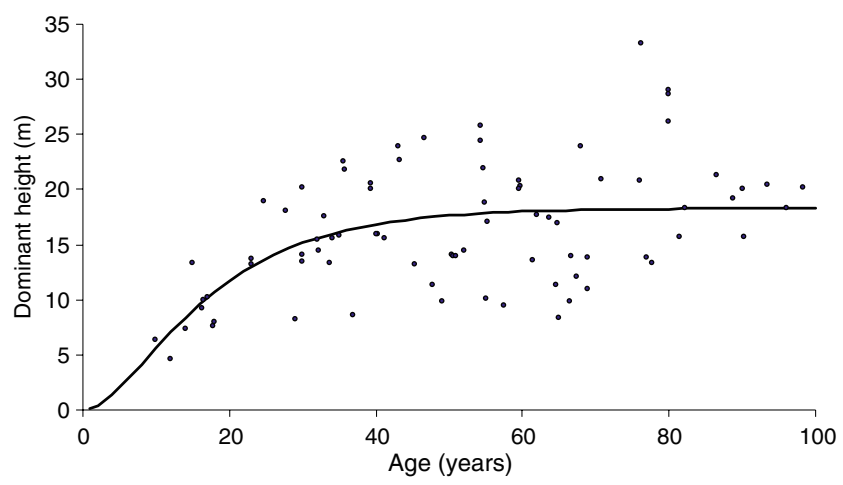

Fig. 1 Age and dominant height of the plots. The Chapman-Richards line is the selected guide curve (Eq. 4) showing the development of dominant height on average site

where $H$ dom is the measured dominant height of the stand of age $T, H \operatorname{dom}(T)$ is the guide curve value for the same age, and $H \operatorname{dom}(50)$ is the guide curve value for 50 years. The dominant height of a stand of age $T$ and site index SI is calculated as follows:

$$
\begin{aligned}
H \text { dom } & =\frac{\mathrm{SI}}{H \operatorname{dom}(50)} H \operatorname{dom}(\mathrm{T}) \\
& =\mathrm{SI} \frac{(1-\exp (-0.080 \times T))^{1.976}}{(1-\exp (-0.080 \times 50))^{1.976}}
\end{aligned}
$$

\subsection{Model for diameter increment}

The diameter increment model was fitted both as a mixed model (Eq. 3) and OLS model. Predictions calculated with the fixed part of the mixed model were poorer (had a higher root mean square error) than predictions of the OLS model. This was the case also when another model was fitted for the plot factor and used for improving the predictions. Therefore, the following OLS model was selected as the diameter increment model:

$$
\begin{aligned}
\ln \left(i_{\mathrm{d}}\right)= & -1.793-0.0221 G-0.0183 \mathrm{BAL}+1.387 \\
& \times \ln (\mathrm{SI})-0.0545 \ln (\mathrm{Slo}+1) \cos (\mathrm{Asp}) \\
& -0.0630 \ln (d)
\end{aligned}
$$

where $i_{\mathrm{d}}$ is 10 -year diameter increment (centimetre), $G$ is stand basal area (square metres per hectare), $B A L$ is basal area of trees larger than the subject tree (square metres per hectare), Slo is steepness of the slope (percent), Asp is aspect in radians $($ AspectInRadians $=6.28 \times($ AspectInDegrees $/ 360))$, and $d$ is breast height diameter (centimetres). The degree of explained variance $\left(R^{2}\right)$ was 0.446 and the standard deviation of residual was 0.573 . In the above model, $d$ represents tree size, SI site quality, and $G$ and BAL represent competition. Figure 3 depicts the effect of predictors on the 10-year diameter increment.

Due to the logarithmic transformation of the predicted variable, a Snowdon correction factor was calculated for the model to remove bias from back-transformed predictions (Snowdon 1991). The correction factor was equal to 1.136. A prediction of 10-year future growth $\left(i_{\mathrm{d} \text {,corrected }}\right)$ is calculated as:

$i_{\mathrm{d}, \text { corrected }}=1.136 \times \exp \left(\ln \left(i_{\mathrm{d}}\right)\right)$

where $\ln \left(i_{\mathrm{d}}\right)$ is the prediction of the logarithmic model (Eq. 7).

In addition to the predictors included in the model, diameter increment correlated significantly and positively with two parent rock types, namely dolomitic limestone and radiolarite. However, since only very few plots represented these rather rare parent rocks, they were not included in the model as predictors. Site index was the strongest individual predictor (Fig. 2). It correlated strongly and positively with soil depth and negatively with slope, which means that these were the main site factors explaining the level of diameter growth of $P$. brutia in Syria. Site index was only weakly correlated with parent rock type, altitude or aspect.

\subsection{Height model}

All height measurements (10-11 measurements per plot) were used to develop an individual-tree height model. The following static model was fitted by using nonlinear regression analysis:

$h=H \operatorname{dom} \times(d / D \text { dom })^{0.543-0.230 d / D \text { dom }}$

where $h$ is tree height (metres), Hdom is stand dominant height (metres), $d$ is diameter at breast height (centimetres), and $D$ dom is dominant diameter (centimetres). The degree of explained variance $\left(R^{2}\right)$ of the model is 0.862 and the standard deviation of residual is $2.12 \mathrm{~m}$. Figure 3 illustrates the effect of predictors on tree height.

\subsection{Self-thinning model}

The model for the self-thinning limit (Fig. 4) is as follows:

$$
\begin{aligned}
\ln \left(N_{\max }\right)= & 10.824-1.828 \ln (\text { Dmean })+0.656 \\
& \times \ln (S I)
\end{aligned}
$$

where $N_{\max }$ is the maximum possible number of trees per hectare, Dmean is non-weighted mean diameter of trees (centimetres) and $S I$ is site index (metres). A Baskerville correction factor (Baskerville 1972) was added to the constant $(0.5 \times$ variance of residual $)$ due to the logarithmic 
Fig. 2 Effect of the predictors on 10-year diameter increment using Eq. 8. The slope is assumed to be $25 \%$ and the values of predictors others than the one on the $x$ axis are equal to their mean values in the modelling data
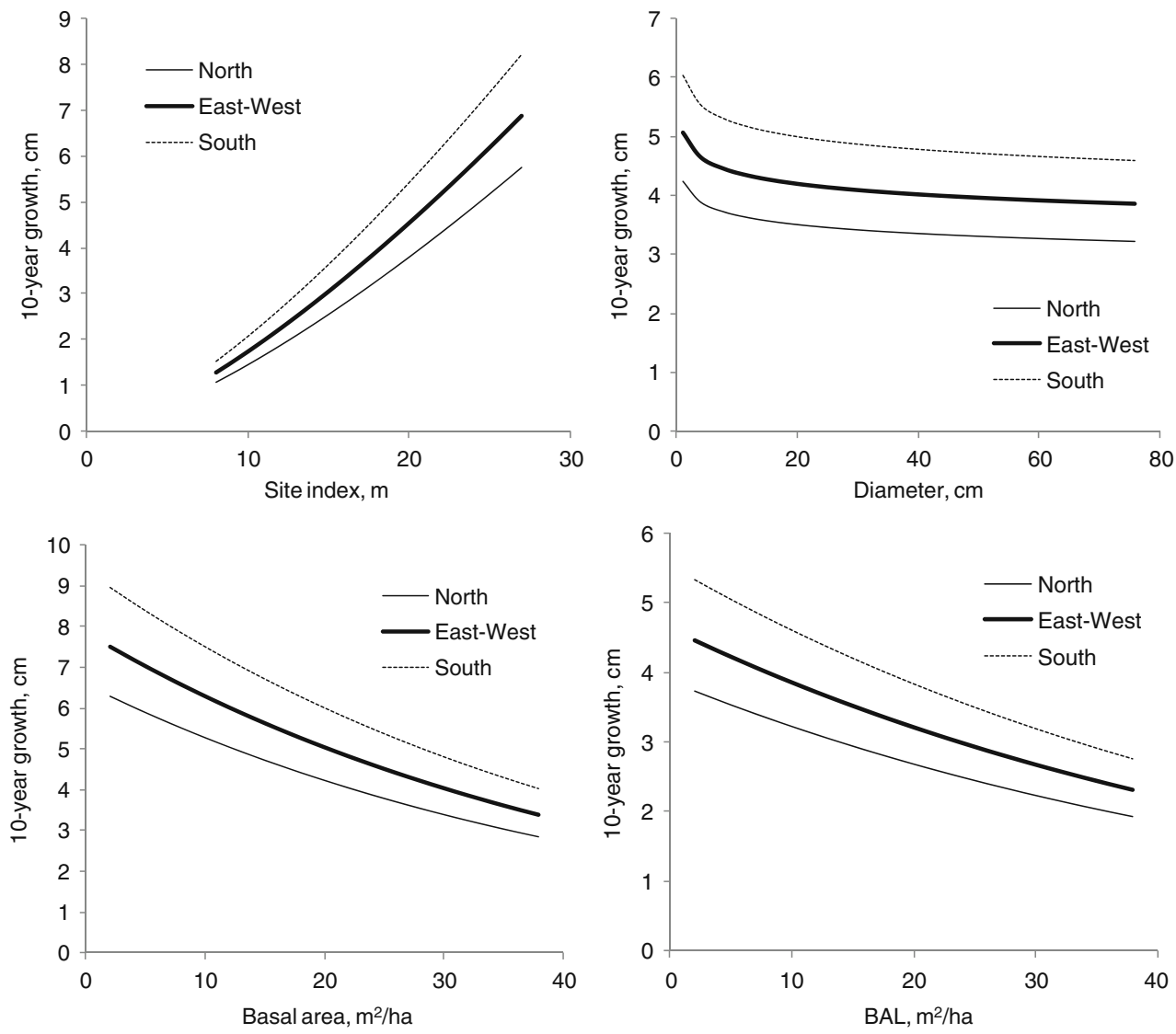

transformation of the predicted variable. The $R^{2}$ of the model is 0.942 and the standard deviation of residual is 0.169 .

\subsection{Use of the models in simulation}

The models can be used to simulate the development of $P$. brutia stands in Syria. The input data consist, for example, of trees measured within a plot. In addition to tree diameters, dominant height (Hdom) and stand age $(T)$ need to be measured. This can be done by measuring the height

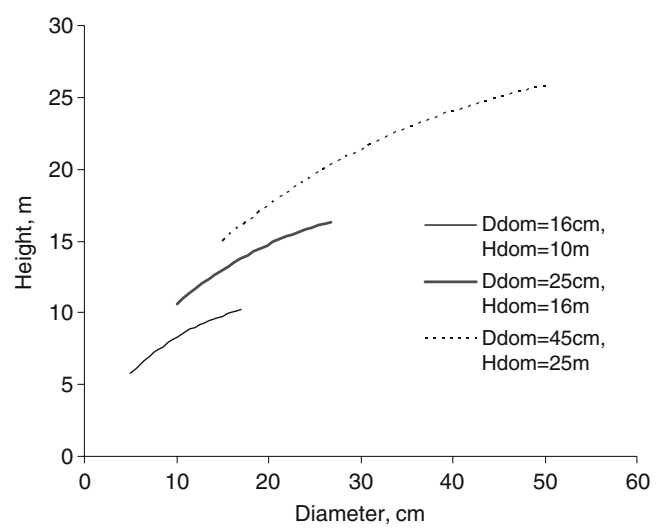

Fig. 3 Effect of tree diameter, dominant diameter and dominant height on tree height according to Eq. 9 and age of a few dominant trees. The site index $(S I)$ is calculated from $H$ dom and $T$.

One 10-year time step is simulated as follows:

1. Increment stand age by 10 years, calculate new $H$ dom $\left(H \mathrm{dom}_{\text {new }}=f\left(T_{\text {new }}, \mathrm{SI}\right)\right)$

2. Increment diameters, calculate mean diameter (Dmean)

3. Calculate self-thinning limit $\left(N_{\max }=f(D\right.$ mean, SI $)$, remove trees if required

4. Calculate Ddom and tree heights $(h=f(d, D d o m$, Hdom))

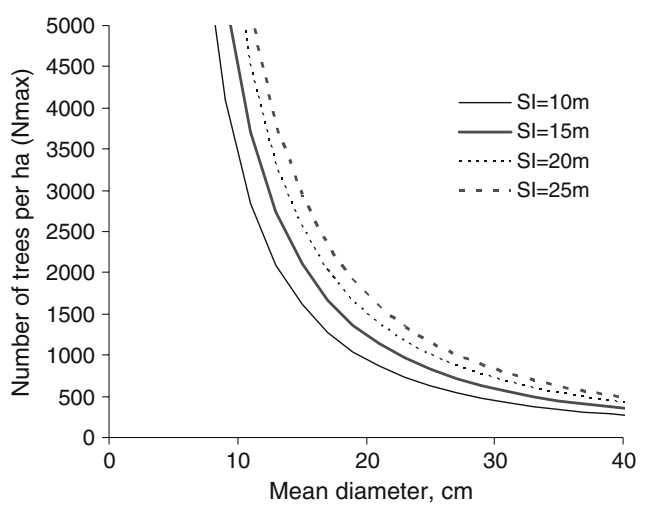

Fig. 4 Dependence of the self-thinning limit on mean diameter and site index according to Eq. 10 
5. Calculate the remaining tree characteristics (stem volume, biomass) and stand characteristics (stand volume etc.).

The models were used to simulate the development of those modelling plots for which two 10-year growth periods were available. The back-tracked diameters of trees 20 years ago were taken as the starting point of simulation. The simulated increment of stand basal area was compared to the observed basal area increment. Mortality was not simulated since the mortality of the plots during the past 20 years is not known. Figure 5 shows that the simulated basal area increment strongly correlates with the observed increment. There is a small positive bias (overestimate) of $2.5 \%$. The bias does not correlate with site index or stand basal area (Fig. 6). An obvious partial reason for the slight overestimate is that the true competition of trees 20 and 10 years ago had been somewhat more than assumed in simulation; in simulation, the past competition was calculated from the past diameters of current survivors, ignoring trees that had died during the past 20-year period.

The models were also used to simulate the development of three plots $(60 \times 60 \mathrm{~m})$ without any thinning treatments. One plot represented very poor sites (SI, $10.5 \mathrm{~m})$, the second medium sites (SI, $18.1 \mathrm{~m}$ ) and the third plot very good sites (SI, $24.1 \mathrm{~m}$ ). In the case of self-thinning, trees that were removed as mortality were selected randomly. Instead of individual trees, diameter classes may also be used in simulation. In this case, with $N>N_{\max }$, mortality can be simulated by multiplying the frequencies of diameter classes by $N_{\max } / N$ where $N$ is the actual number of trees per hectare. It is also possible to remove trees only from the smallest diameter classes. Preliminary volume functions, not yet published, based on 100 felled P. brutia trees were used to calculate stem volume.

The development of the three plots was simulated ten times each to decrease the effect of random tree selection when

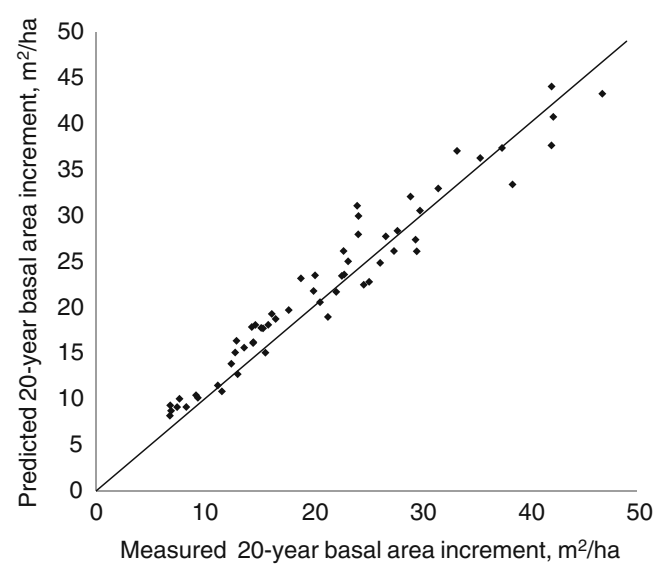

Fig. 5 Correlation between measured and predicted 20-year basal area increment in the study plots


Fig. 6 Correlation of the residual of 20-year basal area increment with site index and stand basal area

simulating mortality. The simulations allowed us to calculate the Mean Annual Increment (MAI) and Current Annual Increment (CAI) curves (Fig. 7). If wood production is maximised and there are no thinnings, the optimal rotation length is the age at which the MAI and CAI curves cross. According to the simulations, the optimal rotation length is 45-50 years on the best sites, 60-65 years on medium sites, and 80 years on the poorest sites. The site productivity, described by the maximum MAI, was $1.5,5.2$ and $10.8 \mathrm{~m}^{3} /$ ha per year for poor, medium and good sites, respectively.

\section{Discussion}

This study presented, for the first time, site index, selfthinning and individual-tree diameter increment and height models for pure even-aged $P$. brutia stands in Syria. According to the site index model, dominant height almost reaches the asymptote at 40 years, and simulations showed that the optimal rotation length of P. brutia on good sites is $45-50$ years. These results suggest that $P$. brutia can be considered as a fast growing pioneer species, as several authors affirm (Isik and Isik 1999; Boydak 2004; Boydak et al. 2006).

The mean annual diameter increment of $P$. brutia trees was $0.42 \mathrm{~cm}$ in the modelling data. Ten-year diameter growth fluctuated between 0.2 and $31.3 \mathrm{~cm}$ depending on site quality, competition and tree size. Furthermore, higher diameter increments were found in southern exposition. Since aspect did not affect in a significant way the site index of $P$. brutia stands in Syria, it is possible to conclude that given a site 

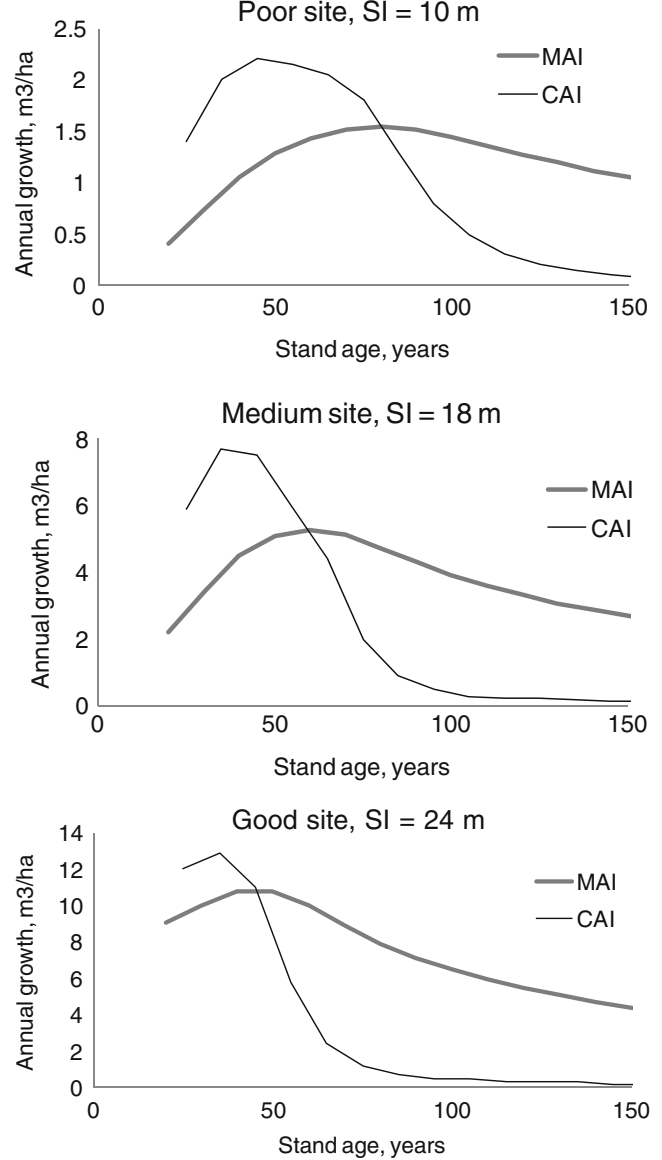

Fig. 7 Mean annual increment (MAI) and current annual increment (CAI) curves of a P. brutia plot representing poor, medium and good sites

index (and the related dominant height development), diameter increment is higher in southern aspects.

OLS model was selected as the diameter increment model instead of a mixed model since the OLS model yielded smaller residuals in growth prediction. Since most plots had two 10-year growth periods, measurement period was also tested as a random parameter in a mixed model, but it was not significant. The possible autocorrelation in growth between the two successive 10 -year periods was ignored in modelling. However, temporal correlation may not be a significant problem if growth intervals of 5 years or more are used (Gertner 1985; Quicke et al. 1994).

Since P. brutia stands are seldom thinned in Syria, it is reasonable to assume that the densest stands had reached the self-thinning limit and the stem exclusion process was ongoing. Field observations verified this conclusion as they showed that there were dead and dying trees in several plots. The self-thinning limit (maximum number of alive trees per hectare) depended on the mean tree diameter of the stand (related to the competition) and on the site index. The model reflected the typical ecology of a lightdemanding species (Gezer 1985; Pantelas 1985; Richardson
1998; Awada et al. 2003), presenting a sharp diminution of the density of living trees when tree diameter increased. Higher maximum tree density was found in good-quality sites and lower density in low-quality sites (Fig. 6). Although some authors mention that the effect of site on tree mortality is unclear (Vanclay 1994) or that mortality begins earlier in good sites (Eid and Tuhus 2001), empirical evidence in Syria reveals that better P. brutia sites can sustain higher basal areas.

Simulations (Fig. 7) were used to demonstrate how the models work together in medium- and long-term growth and yield prediction. The simulations suggest that the fitted models provide realistic predictions of forest stand development and allow one to simulate the development of evenaged P. brutia stand structures in Syrian forests. Nevertheless, it is worth mentioning that there are subjective elements in mortality modelling when selecting plots that are at the self-thinning limit, and mortality simulation when selecting the trees that will die. On the other hand, since thinnings reduce competition and remove weak and suppressed individuals, the role of mortality caused by selfthinning is small if the stand is thinned.

Simulations suggest mean annual volume increments of $10 \mathrm{~m}^{3} / \mathrm{ha}$ in good sites of $P$. brutia, $5 \mathrm{~m}^{3} /$ ha in medium sites and $1.5 \mathrm{~m}^{3} / \mathrm{ha}$ in low quality sites. To maximise wood production, rotation lengths should be $45-50$ years on good sites, 60 years on medium sites and 80 years on poor sites. The above yield estimates agree with previous studies (Gezer 1985; Boydak 2004; Boydak et al. 2006; Palahí et al. 2008).

Ingrowth and regeneration were not measured in this study. Since natural regeneration is generally adopted in natural $P$. brutia forests, appropriate regeneration and management schemes need to be identified. In any case, previous research on regeneration dynamics of $P$. brutia in both post-fire and absence of fire conditions have been done in Greece and Turkey. Natural regeneration of P. brutia seems to be enhanced by a number of adaptations to fire. Several authors agree on describing post-fire height growth, in up to 22-year-old stands of $P$. brutia, as a linear regression model (Spanos et al. 2000; Tavşanoğlu and Gürkan 2009). The dominant height development obtained in Syria (Fig. 1) also suggests this linear or almost linear tendency during the first 20 years. Post-fire survival of pine seedlings could be described following a rectangular hyperbola, and the survival percentage has fluctuated between $28 \%$ (Spanos et al. 2000) and 43\% (Thanos and Marcou 1991), 5 years after fire. In absence of fire, $P$. brutia seems to be a strong invader of open stands where canopy cover is less than 0.65 (Fyllas et al. 2008). Survival of $P$. brutia regenerated in the absence of fire has fluctuated between $23 \%$ and $35 \%$ when applying the shelterwood and the clear-cut regeneration methods, respectively (Boydak et al. 2006). Although these studies conducted in the past could be a valuable basis to be used in Syria, 
additional research on regeneration is needed to complement the model set developed in this study.

The models presented in this research can be further used to develop decision support tools to improve forestry decisionmaking on different scales (stand, forest, landscape) in Syria. In stand-level management planning, these models can be used together with optimization techniques (Palahí and Pukkala 2003) to search for the optimal management schedules for Syrian P. brutia forests.

Acknowledgements This study has been supported by the project 'Development of skills and tools for the sustainable management and preservation of forestry resources, and the revitalisation of rural communities in Syria and Lebanon', co-funded by the Azahar Programme of the Spanish Government Aid Agency 'Agencia Española de Cooperación Internacional para el Desarrollo' and Fundación Biodiversidad (FB).

The authors wish to thank the Government of Syria (Ministry of Agriculture) for the invaluable collaboration.

\section{References}

Awada T, Radoglou K, Fotelli MN, Constantinidou HIA (2003) Ecophysiology of seedlings of three Mediterranean pine species in contrasting light regimes. Tree Physiol 23:33-41

Baskerville GL (1972) Use of logarithmic regression in the estimation of plant biomass. Can J For Res 2:49-53

Boydak M (2004) Silvicultural characteristics and natural regeneration of Pinus brutia Ten.-a review. Plant Ecol 171:153-163

Boydak M, Dirik H, Çalıkoğlu M (2006) Biology and Silviculture of Turkish Red Pine (Pinus brutia Ten.). Ormancılığ 1 Geliștirme ve Orman Yangınları ile Mücadele Hizmetlerini Destekleme Vakfı Yayın1, Lazer Ofset Matbaası, Ankara, Turkey, p. 253

Clutter JL, Forston JC, Piennar LV, Brister GH, Bailey RL (1983) Timber management - a quantitative approach. Willey, New York, $333 \mathrm{p}$

Eid T, Tuhus E (2001) Models for individual tree mortality in Norway. For Ecol Manage 154:69-84

Fady B, Semerci H, Vendramin GG (2003) EUFORGEN Technical Guidelines for genetic conservation and use for Aleppo pine (Pinus halepensis) and Brutia pine (Pinus brutia). International Plant Genetic Resources Institute, Rome, 6 pages

Fischer R, Lorenz M, Köhl M, Becher G, Granke O, Christou A (2008) The Condition of Forests in Europe: 2008 executive report. United Nations Economic Commission for Europe, Convention on Long-range Transboundary Air Pollution, International Co-operative Programme on Assessment and Monitoring of Air Pollution Effects on Forests (ICP Forests), p. 23

Fyllas NM, Dimitrakopoulos PG, Troumbis AY (2008) Regeneration dynamics of a mixed Mediterranean pine forest in the absence of fire. For Ecol Manage 256:1552-1559

Gertner GZ (1985) Efficient nonlinear growth model estimation: Its relationship to measurement interval. For Sci 31(4):821-826

Gezer A., 1985. The sylviculture of Pinus brutia in Turkey . In: CIHEAM, Le pin d'Alep et le pin brutia dans la sylviculture méditerranéenne, Options Méditerranéennes, Série Etudes, Paris, 86(1):55-66

Hynynen J (1993) Self-thinning models for even-aged stands of Pinus sylvestris, Picea abies and Betula pendula. Scand J Forest Res $8: 326-336$
Isik K, Isik F (1999) Genetic variation in Pinus brutia Ten. in Turkey. Silvae Genet 48(6):293-302

Madi S. (1999) In: Fady R. Asmar, Hazme Akyol and Sven Walter (Eds.). 2001 Meeting report: Development and coordination of regional activities on non-wood forest products in Near East countries (Lebanon, May 10-12, 1999). Syria country paper. Forestry Department, FAO, Rome, Italy

Palahí M, Pukkala T (2003) Optimising the management of Scots pine (Pinus sylvestris L.) stands in Spain based on individual-tree models. Ann For Sci 60:105-114

Palahí M, Pukkala T, Kasimiadis D, Poirazidis K, Papageorgiou AC (2008) Modelling site quality and individual-tree growth in pure and mixed Pinus brutia stands in north-east Greece. Ann For Sci 65(5):501

Panetsos K.P., 1985. Genetics and breeding in the group halepensis. In: CIHEAM, Le pin d'Alep et le pin brutia dans la sylviculture méditerranéenne, Options Méditerranéennes, Série Etudes, Paris, 86(1): 81-88

Pantelas V (1985) The forests of brutia pine in Cyprus. In: CIHEAM, Le pin d'Alep et le pin brutia dans la sylviculture méditerranéenne. Options Méditerranéennes, Série Etudes, Paris 86(1):43-46

Peschel W (1938) Die mathematischen Methoden zur Herleitung der Wachstumsgesetze von Baum und Bestand und die Ergebnisse ihrer Anwendung. Tharandter Forstliches Jahrburch 89:169-247

Petrakis PV, Ioannidis C, Zygomala AM (2007) Biotechnology of Pinus brutia and Pinus halepensis as important landscape plants of the East Mediterranean. Tree and Forestry Science and Biotechnology 1(1):26-38

Pienaar LV, Turnbull KJ (1973) The Chapman-Richards generalization of Von Bertalanffy's growth model for basal area growth and yield in even-aged stands. For Sci 19:2-22

Quicke HE, Meldahl RS, Kush JS (1994) Basal area growth of individual trees: a model derived from a regional longleaf pine growth study. For Sci 40(3):528-542

Reineke LH (1933) Perfecting a stand-density index for even-aged forests. J Agric Res 46:627-638

Richardson DM (1998) Ecology and biogeography of Pinus. Cambridge University Press, Cambridge, $527 \mathrm{p}$

Snowdon P (1991) A ratio estimator for bias correction in logarithmic regressions. Can J For Res 21:720-724

Spanos IA, Daskalakou EN, Thanos CA (2000) Postfire, natural regeneration of Pinus brutia forests in Thasos island, Greece. Acta Oecol 21(1):13-20

Strand L (1964) Numerical constructions of site-index curves. For Sci 10(4):410-414

Tavşanoğlu Ç, Gürkan B (2009) Post-fire regeneration of a Pinus brutia (Pinaceae) forest in Marmaris National Park, Turkey. International J Bot 5(1):107-111

Thanos CA, Marcou S (1991) Post-fire regeneration in Pinus brutia forest ecosystems of Samos island (Greece): 6 years after. Acta Oecol 12(5):633-642

Tolunay A, Akyol A, Özcan M (2008) Usage of trees and forest resources at household level: a case study of Açagl Yumrutaç Village from the West Mediterranean Region of Turkey. Res J Forest 2(1):1-14

Trasobares A, Tomé M, Miina J (2004) Growth and yield model for Pinus halepensis Mill. in Catalonia, north-east Spain. For Ecol Manage 203:49-62

Vanclay JK (1994) Modelling Forest Growth and Yield: Applications to Mixed Tropical Forests. CAB International, Wallingford, UK, $312 \mathrm{pp}$.

Yoda K, Kira T, Ogawa H, Hozumi K (1963) Self-thinning in overcrowded pure stands under cultivated and natural conditions. Journal of Biology, Osaka City Univ 14:107-129 